\title{
Sex Associated Differential Expressions of the Alternatively Spliced Variants mRNA of OPRM1 in Brain Regions of C57BL/6 Mouse
}

\author{
Anlong Liu ${ }^{\mathrm{a}}$ Han Zhang ${ }^{\mathrm{a}} \quad$ Fenfen Qin $^{\mathrm{b}} \quad$ Qisheng Wang $^{\mathrm{a}}$ Qinmei Sun ${ }^{\mathrm{a}}$ \\ Shuwu Xie Qian Wang $^{\mathrm{d}}$ Zongxiang Tang ${ }^{\mathrm{c}}$ Zhigang Lu ${ }^{\mathrm{b}}$
}

aThe First Clinical Medicine College, Nanjing University of Chinese Medicine, Jiangsu, bPharmaceutical College, Nanjing University of Chinese Medicine, Jiangsu, 'School of Medicine and Life Science, Nanjing University of Chinese Medicine, Jiangsu, IInternational Education College, Nanjing University of Chinese Medicine, Jiangsu, e Department of Reproductive Pharmacology, Key laboratory of Reproduction Regulation of NPFPC, SIPPR, IRD, Fudan University, Shanghai, China

\author{
Key Words \\ OPRM $1 \cdot$ Sex $\bullet$ Spliced variant $\cdot$ Morphine $\cdot$ Ethology
}

\begin{abstract}
Background/Aims: Opiates are potent analgesics but their clinical use is limited by sexassociated side effects, such as drug tolerance, opioid-induced hyperalgesia and withdrawal reaction. OPRM1, as the main receptor of opioids, plays an important role in the pharmacological process of opioids in rodents and human. We have previously investigated OPRM1, the $\mu$ opioid receptor gene, which have dozens of alternatively spliced variants probably correlating with opioid-induced effects in brain regions of four inbred mouse strains and demonstrated the strain-specific expressions of these splice variants. Also, within a strain, the regional expression patterns of some of the variants were similar while others were opposite. Thus, we are aiming to seek out the relationship between sex differences and these alternatively spliced variants. Methods: The present studies follow a SYBR green quantitative PCR (qPCR) which we had used before to examine the expression of OPRM1 splice variant mRNAs in selected brain regions of male and female C57BL/6 mice. Sex-associated differences in baseline latency, opioid-induced tolerance, analgesia and addiction were examined and determined by Tail-flick test, jumps and statistical analysis. Results: The mRNA levels of opioid receptor gene splice variants in male and female mice showed significant differences among the brain regions, implying region-specific alternative splicing of the OPRM1 gene, which was consistent with our previous study. More importantly, the complete mRNA expression profiles of the OPRM1 splice variants was also gender-specific, suggesting a sexual influence on OPRM1 alternative splicing. Conclusion: In brief, we put forward that the distinctions among baseline latency, opioid-induced tolerance, analgesia and physical dependence in male and female mice might correlate with sex associated differential expressions of OPRM1 gene. (O) 2018 The Author(s)

\begin{tabular}{ll}
\hline Zhigang Lu & Pharmaceutcal College, Nanjing University of Chinese Medicine, \\
& Jiangsu (China) \\
& E-Mail 351534928@qq.com
\end{tabular}
\end{abstract}




\section{Introduction}

Mu-opioid receptor agonists, such as morphine and heroin, which act primarily through $\mu$ opioid receptors [1, 2], are commonly used to treat pain. However, sex differences of side effects and efficacy in opioid antinociception, such as analgesia, tolerance, physical dependence and addiction, have been observed and reported in a variety of mammals in the past three decades [3-7]. With the concept of subtypes of receptors and alternative splicing been proposed by previous studies [8-10], especially successful isolation and determination of $\mu$ opioid receptors variants from a single $\mu$ opioid receptor gene [11-15], we realized that these findings might explain the sex differences partially. It is well known that alternative premRNA splicing generates protein diversity, as well as $\mu$ opioid receptor gene. Our previous studies showed that the mouse, rat and human OPRM1 genes have 29, 16 and 19 splice variants (Fig. S1 - for all supplemental material see www.karger.com/10.1159/000494644

/), respectively, which could be divided into three mojor groups by structures: 1) Full length carboxyl (C-) terminal variants with 7-transmembrane (7-TM) domains; 2) Truncated variants containing 6-TM domains; and 3) Truncated variants containing a single TM $[14,16]$. More significantly, exon 11, which is associated with 6-TM variants, plays an important role in the analgesic actions of morphine-6b-glucuronide (M6G), fentanyl, heroin and IBNtxA, lacking most of the side-effects of $\mu$ opioid drugs, including espiratory depression, nausea, vomiting, constipation, physical dependence, and addictive potential [17-19].

In fact, earlier in the decades ago, Petrovich had put forward sex differences of the pain apperception test in humans and Streicher also found that age and sex affected the duration of hexobarbital anesthesia in rats $[20,21]$. To our knowledge, Compared with female WT mice, male WT mice exhibited higher pain thresholds and enhanced opioid receptor-induced antinociception [6, 22-24], in contrast, mixed KOPR/MOPR ligands have been found to produce greater analgesia in women than men [25]. There were numerous mechanisms and pathways explaining the sex differences between antinociception, tolerance, physical dependence, addiction and withdrawal, for example, the GIRK2-null mutation reduced the "pain" threshold in male but not in female mice, effectively eliminating the sex differences in pain threshold [22]. On one hand, it had been demonstrated that the ventolateral periaqueductal gray (vlPAG) produced comparable antinociception in female and male rats despite fewer vlPAG output neurons projecting to the rostral ventromedial medulla in male compared to female rats, but antinociception produced by inhibition of GABAergic neurons could produce greater antinociception in males [23]. On the other hand, Scott proposed that only estrus females' response to morphine was lower than that of males and females have fewer ventral periaqueductal gray (vPAG) mu opioid receptors than males, suggesting that ovarian hormones and PAG mu opioid receptor density contribute to sex differences in antinociception produced by morphine [6]. An investigation focusing on KPOR-mediated effects indicated that The kappa opioid receptor (KOPR) system is a potential therapeutic target for pain, mood disorders and addiction, which might be mediated by sex chromosomes, gonadal hormonal influence on organization (circuitry) and/or acute hormonal influence on KOPR expression, distribution and localization [25]. Also, there were studies focusing on the CA3 area of hippocampus because of numerous sex differences in hippocampal-dependent behavior and Lauren $\mathrm{C}$ et al. found strong MOR regulation of the mossy fiber transmission only in females and a novel DOR-dependent form of MF LTP specific to proestrus which might lead to sex differences [26]. As for sex chromosome genes, it was proposed that sex differences in pain might stem not only from the action of gonadal hormones, but also from the sex-specific action of $\mathrm{X}$ and $\mathrm{Y}$ genes, which are irresponsible for gonadal sex and identification of sex chromosome genes could contribute to better pain therapy in females and males [24]. Besides, sex differences also correlate with melanocortin-1 receptor [27, 28], estrogen receptor [7], phosphorylation of p44/42 MAP kinase [29] and the Neuroanatomy [30], and disagreement among such studies may result from differences in the type/intensity of the nociceptive stimulus, efficacy of the mu agonist, use of awake vs. anesthetized animals, estrous phase of females, and genotype (strain/vendor) of the rodent [5, 31, 32]. 
Our previous studies suggested that the mRNA expression of many variants was regionspecific and strain-specific as well using SYBR green quantitative PCR (qPCR) assays, which is more accurate, reliable and sensitive than regular RT-PCR approaches [33]. It has been demonstrated that sex differences in the effects of peripheral MOR agonists is partly mediated by sex differences in the changes of MOR expressions [34], tolerance/dependence results from different adaptational strategies (chronic systemic morphine influenced levels of MOR splice variant mRNA) in males and females [35], MOR expression in the PAG was sexually dimorphic contributed to the observed sex differences in morphine potency [36] and testosterone plays a key role in the regulation of MOR under inflammatory conditions and these differences in the antihyperalgesic effects of peripherally administered opioids are mediated by peripheral opioid receptor expression levels partially [37]. Thus, we determined to explore the different effects of $\mu$ opioid receptor agonists and aimed to investigate the mRNA expression of MOR variants of different brain regions by SYBR green quantitative PCR (qPCR) in male and female mice and prepared to figure out some certain relationships between MOR variants and these sex-associated reactions.

\section{Materials and Methods}

\section{Animals}

Age matched (8-10 weeks) C57BL/6 adult male and female mice used in the present study were purchased from Model Animal Research Center of Nanjing University. All mice were housed in groups of 3-5, separated based on sex and litter, maintained on a 12-hour light / 12-hour dark cycle, and given ad libitum access to food and water in a temperature-controlled room. Estrous phase was not measured in order to prevent heightened stress in female mice [23,37]. All procedures were approved by Nanjing University of Chinese Medicine Animal Care and Use Committee. Efforts were made to reduce the number of animals used in these experiments and to minimize any possible suffering of mice by testing the subjects in two or three conditions on different days.

\section{Painful sensibility, morphine analgesia, tolerance and physical dependence}

To explore sex differences of sensibility, we picked out adult male and female mice randomly and the pain threshold (baseline latency) was determined and recorded using a radiant-heat tail-flick assay, with a maximal latency of 10 seconds (the heat intensity was set to 26 watt so that the baseline latencies were 2.0 -4.0 seconds) to minimize tissue damage, as previously described [18, 22, 38, 39]. Tolerance in the targeted mice was induced by twice-daily injections with morphine $(1,3,10 \mathrm{mg} / \mathrm{kg}$, s.c., respectively) for 5 days and the results were calculated as the percentage of maximum possible effect (\% MPE) as follows: [(latency after drug - baseline latency) / (10 - baseline latency) $\times 100]$. Morphine analgesia was examined once per day and the total analgesic potency was measured by AUC (the area under the dose-response curve, a measure that integrates the responses across all of the tested doses and days). Morphine dependence was determined on day 5 with naloxone (s.c., $1 \mathrm{mg} / \mathrm{kg}$ ) injections 3 hours after the last morphine treatment. Mice used to precipitate withdrawal were treated with morphine $(10 \mathrm{mg} / \mathrm{kg}$ twice daily for 5 days $)$ previously. The number of jumps within 15 minutes immediately following the naloxone injection was used for the measurement of withdrawal.

\section{Tissue dissection, RNA extraction and reversetranscription (RT)}

Brain regions including the prefrontal cortex (Pfc), thalamus (Tha), hypothalamus (Hyp), hippocampus (Hip), periaqueductal gray (PAG), and ventral tegmental area (VTA) were dissected on a mouse Plexiglas brain mold using the atlas of Paxinos and Franklin [40] as a reference (Fig. S2). The spinal cord (Spc) from L1 to L5 was also dissected. The dissected tissues were immediately homogenized in TRIzol Reagent (TaKaRa). The homogenates were stored at $-80^{\circ} \mathrm{C}$ until further RNA isolation. 2-3 mice were pooled for each region, and a total of 8-10 mice used for each gender. Total RNAs were extracted using miRNeasy kit (TaKaRa) following manufacture protocol. RNA concentrations were determined using a Qubit 2.0 Fluorometer (Invitrogen). RNAs were first treated with TurboDNA free reagent (TOYOBO) following the manufacture's protocol to remove potentially contaminating genomic DNA, and reverse transcribed with Superscript II 


\section{Cellular Physiology Cell Physiol Biochem 2018:50:1441-1459 and Biochemistry Published online:26 October $2018 \begin{aligned} & \text { DOI: 10.1159/000494644 } 2018 \text { The Author(s). Published by S. Karger AG, Basel } \\ & \text { www.karger.com/cpb }\end{aligned}$}

Liu et al.: Sex Differences of OPRM1 in Mouse Brain Regions

reverse transcriptase (TOYOBO) and random hexmers. The first-strand cDNA was then used as templates in SYBR qPCRs.

\section{Primers design and SYBR green $q P C R$}

Since many exons are shared by different variants, it is difficult to design the short amplicon required for an efficient qPCR using the TaqMan assay for most of the splice variants. SYBR Green qPCR offers more flexibility in terms of amplicon size and thermocycle conditions. Using primer design tools in GeneRunner and VectorNTI, we designed appropriate primers for each splice variants, optimized qPCR parameters, such as annealing temperature and extension time, and obtained reasonable amplification efficiency by generating standard curves using 5-7 serial 10-fold dilutions of corresponding cDNAs as templates (Table S1). In most cases, we designed primers targeting exon-exon junctions or crossing at least two exons to obtain specific amplification. Specificities of the primers were verified by qPCRs using plasmid constructs containing corresponding variant cDNAs, and by melting curve analysis and agarose gel analysis after qPCR. Table S1 lists the names, sequences and location of primers, as well as amplicon size, efficiency and PCR parameters, for all 30 splice variants. Two workstations in two separate rooms were used exclusively for qPCR to avoid cross contamination. Three reference genes, succinate dehydrogenase subunit A (SDHA), TATA box binding protein (TBP) and glycerakdehyde 3-phosphate dehydrogenase (G3PDH), were selected to obtain normalization factors using the formula [41-43]: Normalization factor $(\mathrm{NF})=(\mathrm{C}(\mathrm{t}) \mathrm{SDHA} \times \mathrm{C}(\mathrm{t})$ TBP $\times \mathrm{C}(\mathrm{t}) \mathrm{G} 3 \mathrm{PDH})^{1 / 3}$. All qPCRs were performed using SYBR ${ }^{\circledR}$ Premix Ex Taq ${ }^{\mathrm{TM}}$ II (Tli RNaseH Plus) (TaKaRa) with LightCycler 480 II System (Roche Diagnostics, Germany) .Normalized expression (NE) or expression level for each variant was calculated using the formula [41]: $\mathrm{NE}_{\text {variant }}=\mathrm{E}^{-(\mathrm{C}(\mathrm{t}) \text {-variant }-\mathrm{C}(\mathrm{t}) \mathrm{NF})}\left(\mathrm{E}^{-\triangle \mathrm{C}(\mathrm{t})}\right)$, where $\mathrm{E}$ is efficiency. Fold change (FC) was calculated using the formula [41]: $\mathrm{FC}=\mathrm{NE}_{\text {variant }} / \mathrm{NE}_{\text {reference, }}$, where a reference was $\mathrm{mE} 1 / 2$ and is was defined as $100 \%$. $\mathrm{mE} 1 / 2$ amplified with primers from exon 1 to exon 2 represented all C-terminal variants, including the original mMOR-1. Although the original mMOR-1 transcribed through the exon 1 promoter is by far the most abundant, it is difficult to design a pair of specific primers for amplifying the exon 1 promoter-driven mMOR-1, since exons 1-4 are shared by several other variants as well.

\section{Statistical analysis}

All mice were randomized and assigned to groups. Some, but not all, experiments were performed under blinded conditions. All statistical analysis was carried out using GraphPad Prism 6.0 and 7.0. Student's t test was used for ethology and 2-way ANOVA was performed with Tukey's multiple comparisons test for analyzing qPCR data. Data are represented as the mean \pm S.E.M. from at least 3 independent experiments. Statistical significance was set at $\mathrm{P}<0.05$. The results are are listed in Table S3.

\section{Results}

Sex differences in baseline responses, morphine-induced analgesia, tolerance and addiction

To determine that sex differences exactly exist between B6 mice, we examined the baseline responses to the tail-flick test and found that male mice displayed longer latencies to tail withdrawal compared to female mice (mean latency of male: $3.056 \mathrm{~s}$, mean latency of female: 2.365 s, as shown in Fig. 1a), i.e., female mice were more sensitive to the noxious heat stimulus. Next, we investigated sex differences in the antinociceptive potency of systemic morphine of different doses $(1 \mathrm{mg} / \mathrm{kg}, 3 \mathrm{mg} / \mathrm{kg}$ and $10 \mathrm{mg} / \mathrm{kg}$ ) in accordance with previous studies (the curve of tail-flick test is gradually ascending [22] and morphine ED50 is in the range of $2.3 \pm 0.2 \mathrm{mg} / \mathrm{kg} \sim 2.9 \pm 0.3 \mathrm{mg} / \mathrm{kg}$ [38]), since morphine predominantly targets the opioid receptor. As shown in Fig. 1d, the highest dose of morphine (10 mg/kg) elicited the MPE score $100 \%$ (limited to $10 \mathrm{sec}$ to prevent tissue injury) in both male and female mice on day 1 , whereas the dose of morphine $(3 \mathrm{mg} / \mathrm{kg})$ and the dose of morphine $(1 \mathrm{mg} / \mathrm{kg})$ revealed stronger analgesic potency in male mice compared with female mice (Fig. 1e, ${ }^{* *}: \mathrm{P}<0.01$; Fig. 1f, $\left.{ }^{*}: \mathrm{P}<0.05\right)$. On day 2, the dose of morphine $(10 \mathrm{mg} / \mathrm{kg}$ ) retained potent analgesic effect in spite of the higher MPE score in male mice compared to female mice in Fig. 1d (the P value has no statistical significance). However, the analgesia effect was still higher in male mice than female mice which received morphine of $3 \mathrm{mg} / \mathrm{kg}$ (Fig. 1e, *: 
Fig. 1. Baseline latency, morphin e-ind u c ed analgesia, tolerance and addiction elicited by thermal stimulus. a. Baseline latency is determined by the mean of tail-flick threshold values \pm S.E.M. b. M or p hin e - in d u c e d physical dependence is reflected by the number of jumps within 15 minutes immediately following the naloxone injection. d, e and f. Analgesic effect induced by morphine (10 $\mathrm{mg} / \mathrm{kg}, 3 \mathrm{mg} / \mathrm{kg}$ and $1 \mathrm{mg} /$ $\mathrm{kg}$ ) is measured by the percentage of maximum possible effect (\% MPE). c. AUC reveals the respective and total analgesic potency of morphine $(10 \mathrm{mg} / \mathrm{kg}$, $3 \mathrm{mg} / \mathrm{kg}$ and $1 \mathrm{mg} / \mathrm{kg}$ ). Significant difference was calculated by Student's t test. Comparison of male and female mice: *: $\mathrm{P}<0.05$; **: $\mathrm{P}<0.01$; ***: $\mathrm{P}<0.001$; comparison of day 1 and another day in mice of the same gender: \#: $\mathrm{P}<0.05$; \#\#: $\mathrm{P}<0.01$; \#\#\#: $\mathrm{P}<0.001$. a T. flick threshold
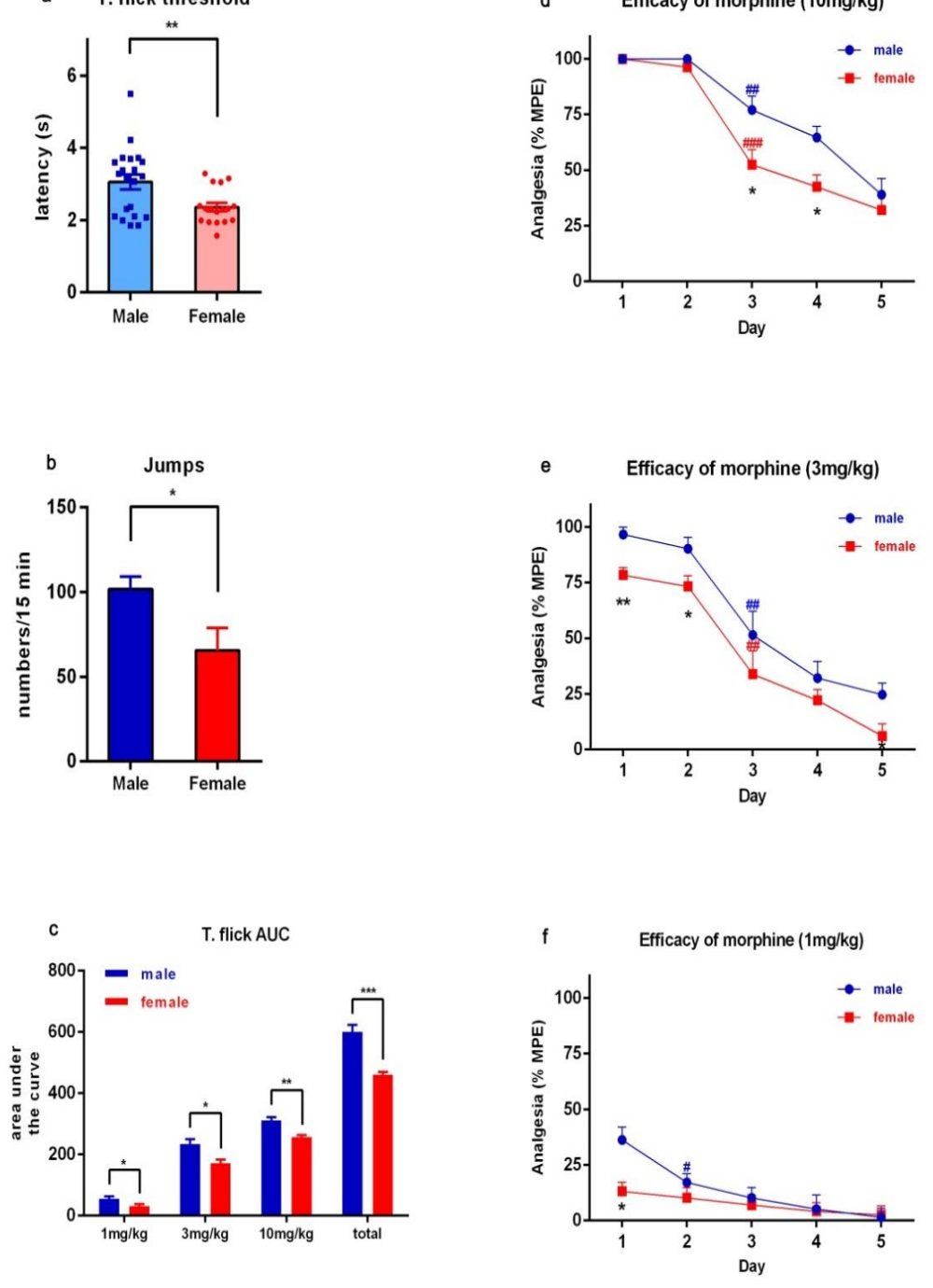

$\mathrm{P}<0.05$ ), and male mice treated with morphine of $1 \mathrm{mg} / \mathrm{kg}$ presented drug tolerance (Fig. $1 \mathrm{f}$, \#: $\mathrm{P}<0.05$ ) on day 2 . On day 3 , mice treated with morphine of $10 \mathrm{mg} / \mathrm{kg}$ and $3 \mathrm{mg} / \mathrm{kg}$ both persented obvious drug tolerance (Fig. 1d, \#\#: $\mathrm{P}<0.01$, \#\#\#: $\mathrm{P}<0.001$; Fig. 1e, \#\#: $\mathrm{P}<0.01$ ), in contrast, sex difference of morphine analgesia appeared in mice received morphine of 10 $\mathrm{mg} / \mathrm{kg}$ for the first time (Fig. $1 \mathrm{~d},{ }^{*}: \mathrm{P}<0.05$ ) whereas sex difference of morphine analgesia disappeared in mice received morphine of $3 \mathrm{mg} / \mathrm{kg}$ (Fig. 1e) and the dose of morphine (1 $\mathrm{mg} / \mathrm{kg}$ ) showed too weak analgesia effect to prevent pain conduction (Fig. 1f). On day 4, only mice received morphine of $10 \mathrm{mg} / \mathrm{kg}$ presented sex difference of analgesia (Fig. 1d, *: $\mathrm{P}<0.05)$. On day 5 , sex difference of analgesia appeared again in mice treated with morphine of $3 \mathrm{mg} / \mathrm{kg}$, exclusively (Fig. 1e, *: P<0.05). To compare statistically the magnitude of the morphine analgesia, we calculated the area under the dose-response curve (AUC, a measure that integrates the responses across all of the tested doses on different days), respectively (Fig. 1c), and found that the analgesic effect of morphine is absolutely more potent in male mice compared with female mice. Morphine physical dependence was assessed by naloxoneprecipitated withdrawal after chronic morphine treatment and results were shown as the number of jumps within 15 minutes immediately following naloxone injection. Consistent with humans [7], our data showed that male mice were more likely to generate morphine addiction compared with female mice (Fig. 1b). In general, our data revealed that there are KARGER 


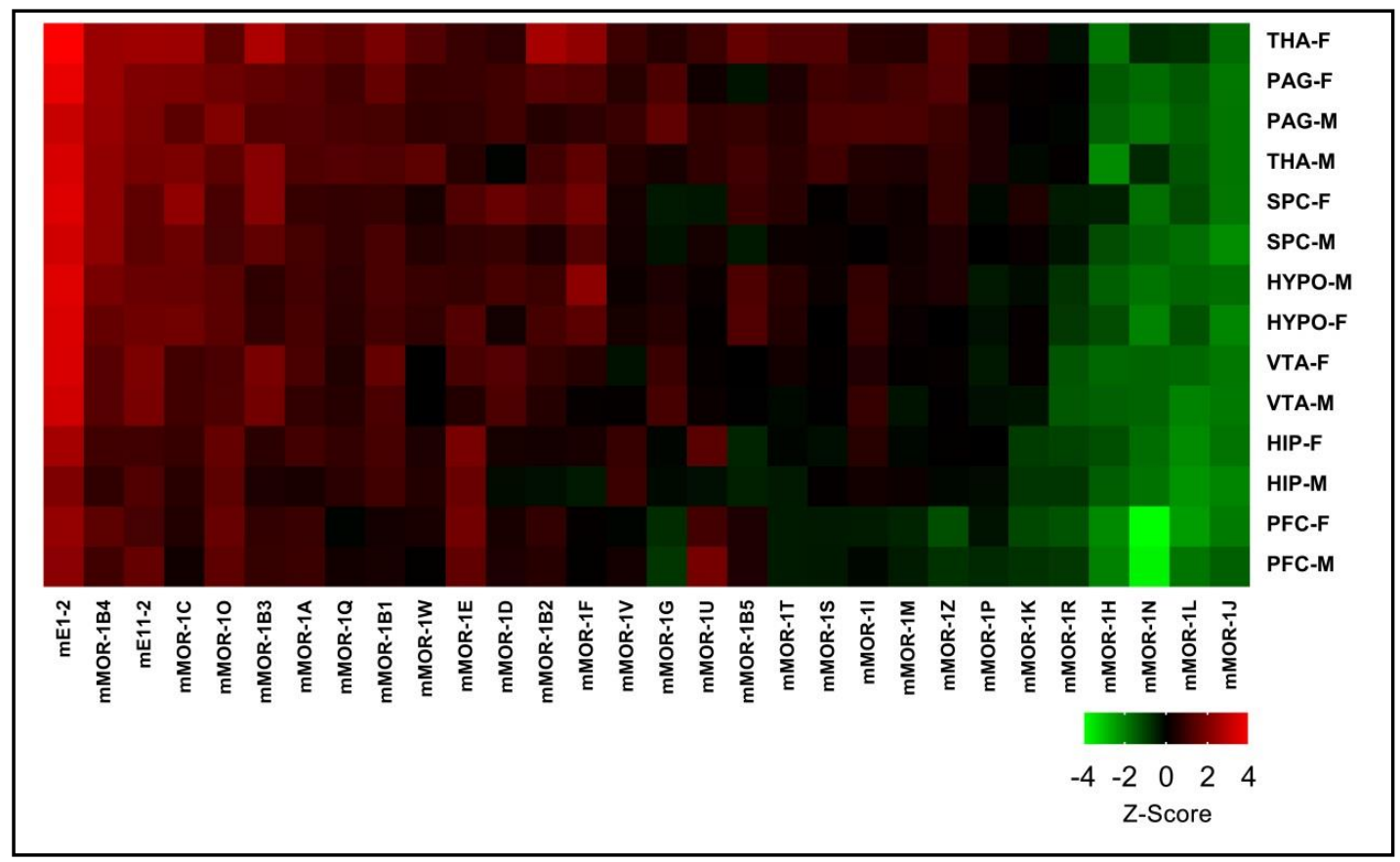

Fig. 2. Heatmap of expression levels of OPRM1 splice variant mRNAs. The heatmap was generated by clustering Z-scores calculated from the values ( $\log _{2} \mathrm{E}^{-\Delta C(\mathrm{t})}$ of individual variants across different genders/ regions using $\mathrm{R}$ statistical language, and plotting based upon expression levels among the variants with enhanced heatmap function from GraphPad Prism 7.0. M: male; F: female. Expression level was indicated by Z-score.

significant sex differences of baseline latency, morphine analgesia, tolerance and physical dependence between male and female mice, although the drug tolerance day of morphine dose $10 \mathrm{mg} / \mathrm{kg}$ and $3 \mathrm{mg} / \mathrm{kg}$ was both on day 3 and the reason that female mice received morphine of $1 \mathrm{mg} / \mathrm{kg}$ did not show drug tolerance might be that the dose was too low to elicit significant difference of MPE.

Expression levels of OPRM1 splice variants mRNA in Brain Regions of male and female C57BL/6 Mice

Previous studies investigating sex differences of $\mu$ opioid agonist analgesia were always focusing on the expression of $\mu$ opioid receptor (probably only a matter of MOR1) in Periaqueducatal Gray (PAG) by ethology, pharmacology, neuroanatomy, immunohistochemistry and immunofluorescence [6, 23, 30, 36, 37]. Aiming to demonstrate the relationship between OPRM1 splice variant and sex differences and using the established RT-SYBR green qPCR assays, we examined the expression levels of OPRM1 splice variants mRNA in six brain regions and spinal cord of male and female C57BL/6 Mice. The overall expression levels among the variants are shown in a heatmap clustered based upon Z-scores from the values $\left(\left(\log _{2}\left(\mathrm{E}^{-\Delta C(\mathrm{t})}\right)\right.\right.$ of individual variants across different gender / regions, plotting from the lowest level (left, green) to the highest level (right, red) (Fig. 2) (All $\mathrm{E}^{-\Delta C(t)}$ values are listed in Table S2)). The heatmap reveals a wide range of expression levels among the variants, as indicated by Z-score values from $<-4$ to $4>$. mE1-2, which represents the entire repertoire of full-length 7-TM variants, was expressed at the highest level in all brain regions, whereas mE11-2, which represents the entire repertoire of truncated 6-TM variants, was expressed at a lower level than mMOR-1B4, mMOR-1C et al. of some brain regions, indicating that the full-length 7-TM variants are abundant and the expression level of some single 7-TM variant is especially high. The expression of the other splice variants differed dramatically among the regions and gender. 
Fig. 3. Expression levels of selected eleven splice variants in brain regions of male and female mice. Expression levels of $(-1) /\left(\log _{2}\left(E^{-\Delta C(t)}\right)\right)$ of selected variants is plotted across regions using MS excel.

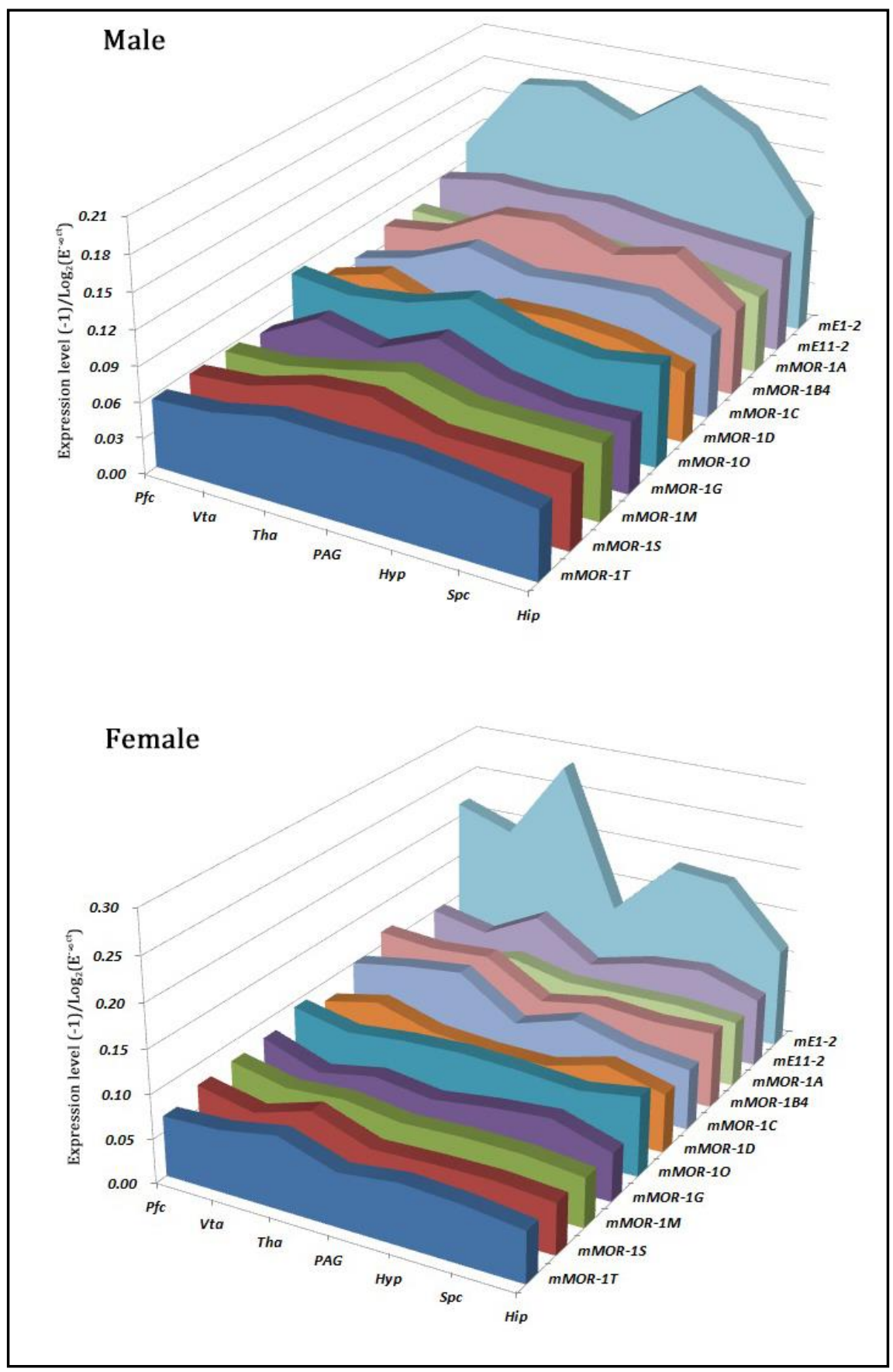

To visualize expression patterns more closely, we compared five C-terminal splice variants and two 6-TM and two 1-TM variants, as well as mE1-2 and mE11-2, by plotting their $(-1) / \log _{2}\left(E^{-\Delta C(t)}\right)$ values in the brain regions (Fig. 3). The various splice variant expression levels among the brain regions ranged widely but the curve was not as checkered as our previous data [33], probably on account of that our present brain regions did not include striatum (Str), brain stem (BS), cerebellum (Cb) and whole brain (WB). For instance, in the spinal cord of male mice, the relative expression levels ranged from $0.04 \%$ for mMOR-1B5 to $11.74 \%$ for mMOR-1B4, when their $E^{-\triangle C(t)}$ values were used to compare with those of mE1-2 designated as $100 \%$ (Fig. 3 \& Table S2). The full length C-terminal splice variants mMOR-1C, mMOR-10 and mMOR-1B4 in female mice were highly expressed among most brain regions, 


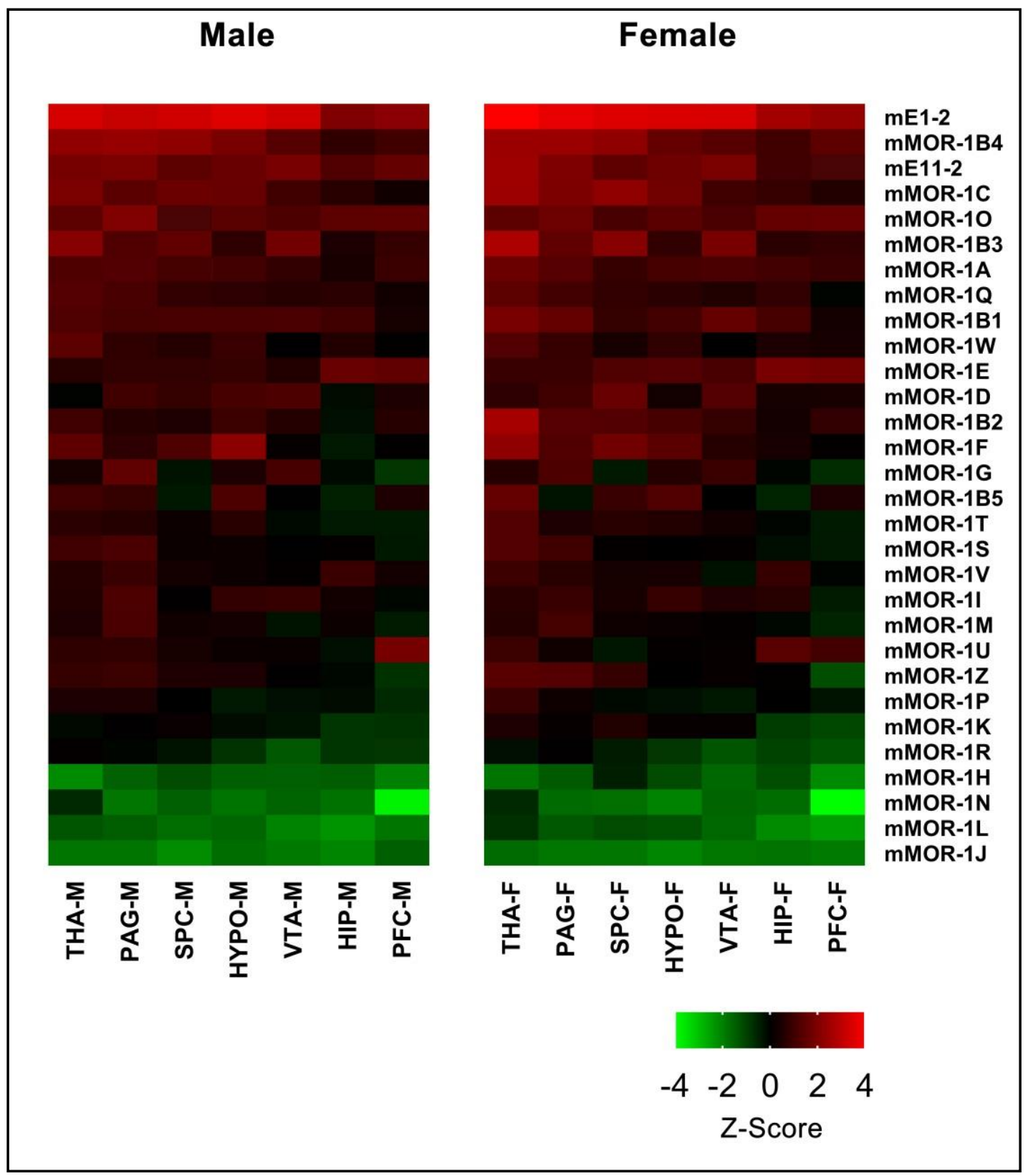

Fig. 4. Heatmap of regional expression OPRM1 splice variant mRNAs. The heatmap was generated by clustering Z-scores calculated from the values $\left(\log _{2} \mathrm{E}^{-\Delta c(t)}\right)$ of individual variants across different genders/ regions using R statistical language, and plotting based upon individual brain regions within male or female mice with enhanced heatmap function from GraphPad Prism 7.0. M: male; F: female. Expression level was indicated by Z-score.

corresponding to approximately $8-10 \%$ of mE1-2 levels in their $E^{-\Delta C(t)}$ values (Fig. 3 \& Table S2). On the other hand, in female mice the levels of the truncated 6-TM variant mMOR-1G and mMOR-1M and single TM variants, mMOR-1S and mMOR-1T, and the full length mMOR1D, ranged from about $0.2 \%$ to $2 \%$ of mE1-2 levels (Fig. 3 \& Table S2). Similar expression patterns were observed in male mice (Fig. 3 \& Table S2). Broadly speaking, most of the full length C-terminal splice variants were highly expressed in selected brain regions, whereas mRNA expression levels of the truncated 6-TM variants and single TM variants were mixed. 


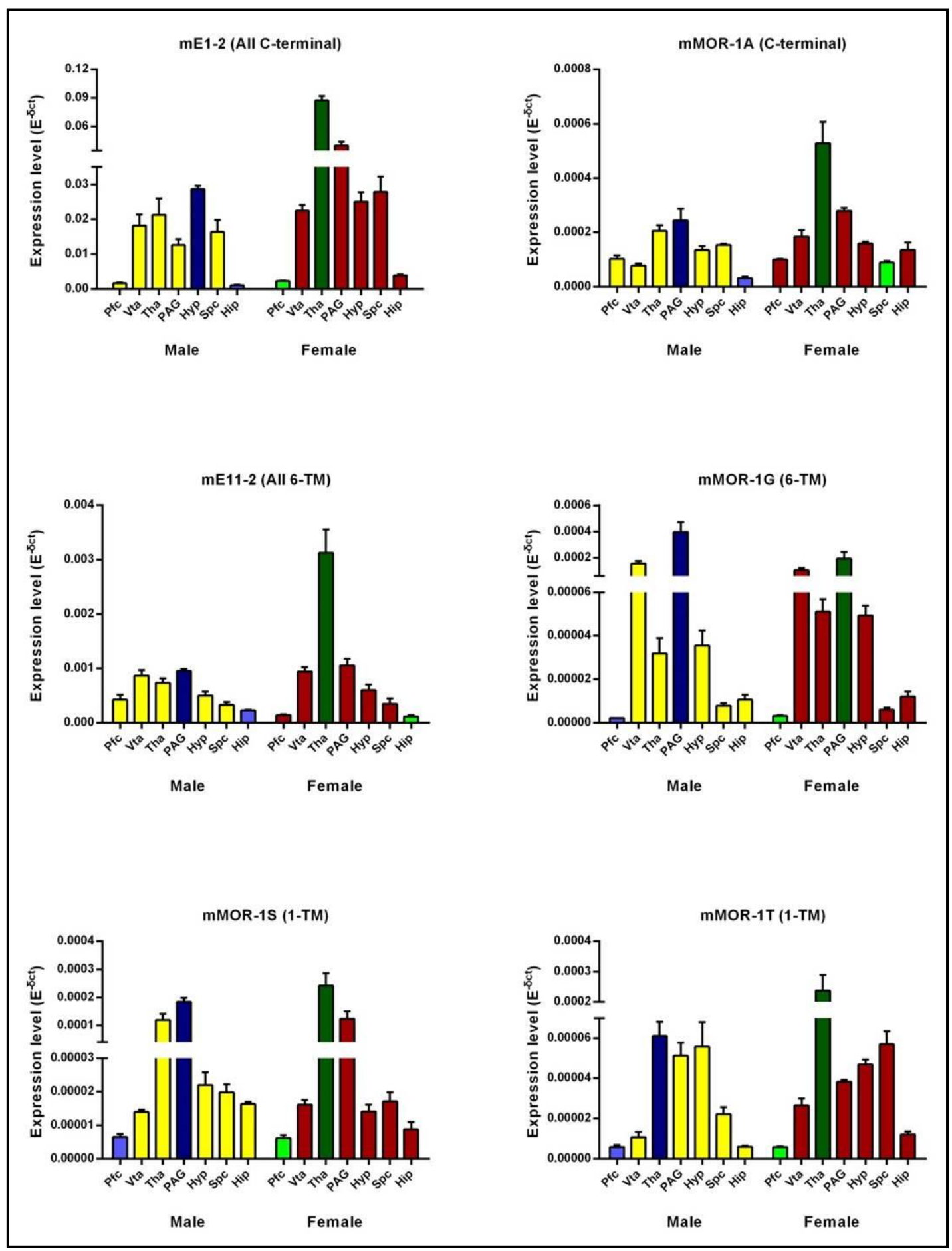

Fig. 5. Region-specific expressions of ten-selected OPRM1 splice variants. Each panel represents the regional expression of one variant in male and female mice. Yellow bar: male mice; Red bar: female mice. Dark blue bar: highest expression in male mice. Light blue bar: lowest expression in male mice. Dark green bar: highest expression in female mice. Light green bar: lowest expression in female mice. Bars represent the mean of $E^{-\Delta C(t)}$ values \pm S.E.M.. mE1-2 represents all full-length 7-TM variants and $m E 11-2$ represents all truncated 6-TM variants respectively. Significant difference was calculated by Two-way ANOVA with Tukey's multiple comparisons test for each variant (Prism 6.0). The results of the statistical analysis were listed in Table S3. The expression profiles of the other 24 OPRM1 splice variants are shown in Fig. S3, S4, S5 \& S6. 


\section{Cellular Physiology Cell Physiol Biochem 2018;50:1441-1459

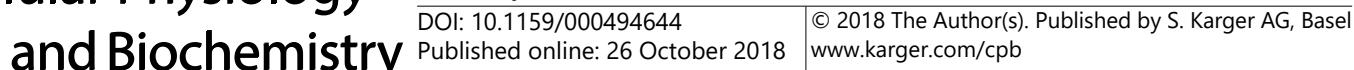 \\ Published on}

Region-specific expressions of OPRM1 splice variants $m R N A$ in male and female C57BL/6 Mice

Overall, among the vast majority of OPRM1 variants, the mRNA expression was higher in the Tha and PAG compared with that in the Hip and Pfc, though there were still major differences in the regional expression of the variants. We segregated male and female mice to generate a heatmap showing the overall differential expression pattern of all variants across the brain regions (Fig. 4), which eliminated gender interference. Plotting the expression level $\left(E^{-\Delta C(t)}\right)$ for each variant among the regions illustrates the differences quantitatively and some variants were sorted to provide a visual pattern of regional expression (Fig. 5, S3, S4, S5 \& S6). For example, the expression pattern of the full length variant mMOR-1B4 differed among most of the brain regions. Its levels were high in the Tha and PAG of all mice, with lower levels in the Hip and Pfc. In contrast, mMOR-1E expression in both male and female mice was highest in the Hip with similar high levels in the Pfc, and mMOR-1U expression in the Hip and Pfc of female mice and the Pfc of male mice was higher compared with that in the Tha and PAG. Nevertheless, mMOR-1D and mMOR-1H expression of female mice were highest in the Spc, in the meanwhile, mE1-2 and mMOR-1F expression of male mice were highest in the Hyp, MOR1-D expression of male mice were highest in the VTA, respectively.

Within male or female mice, the regional expression patterns of some of the variants were similar. For example, mMOR-1A, mMOR-1B1, mMOR-1B2, mMOR-1B4, mMOR-1M, mMOR-1P, mMOR-1Q, mMOR-1R, mMOR-1S, mMOR-1W and mMOR-1Z expression of female mice were highest in the PAG and Tha (Fig. 4). In the PAG and Tha of male mice, a similar expression pattern was observed in some other variants, for example, mMOR-1A, mMOR1B4, mMOR-1L, mMOR-1M, mMOR-1P, mMOR-1Q, mMOR-1R, mMOR-1S and mMOR-1Z expression were highest (Fig. 4). However, no matter in male or female mice, the number of the variants which were expressed most abundant in the PAG and Tha was nine (mMOR-1B1, mMOR-1B2, mMOR-1B3, mMOR-1C, mMOR-1L, mMOR-1N, mMOR-1Q, mMOR-1T, mMOR$1 \mathrm{~W}$ ) and five (mMOR-1B4, mMOR-1G, mMOR-1I, mMOR-1M, mMOR-10), respectively, while the number of the variants which were expressed oppositely in the Hip and Pfc was four (mMOR-1B2, mMOR-1B3, mMOR-1B4, mMOR-1B5) and eleven (mMOR-1B1, mMOR-1C, mMOR-1G, mMOR-1I, mMOR-1K, mMOR-1M, mMOR-1N, mMOR-1Q, mMOR-1S, mMOR-1T, mMOR-1Z), respectively (Fig. 5, S3, S4, S5 \& S6). Though the mRNA levels of most variants were expressed diversely correlating with brain regions, there were still some variants which did not display regional differences statistically (Table $S 3, P>0.05$ ), including mMOR1B1, mMOR-1B2, mMOR-1B3, mMOR-1H, mMOR-1K, mMOR-1T of male mice and mMOR1I, mMOR-1J (this data might not be convincing since the mRNA level of mMOR-1J was too low) of female mice. Also, mE11-2, mMOR-1C, mMOR-1L and mMOR-1Z expression of male mice did not show regional differences apparently (Table S3). Intriguingly, in male mice, mMOR-1D expression was highest in the VTA with lowest levels in the Hip while mMOR-1E expression levels in these same regions were opposite and other variants showed the same patterns of expression levels among the regions.

In general, variant expression was low in the Pfc and Hip, consistent with our previous study [33] and prior in situ hybridization studies with the full-length MOR-1 probe [44]. However, this was not uniformly the case. In male mice, mMOR-1U and mMOR-1J expression was greatest in the Pfc (Fig. S5), and in the Hip, mMOR-1E and mMOR-1V expression of male mice and mMOR-1E and mMOR-1U expression of female mice were both greatest (Fig. S4 \& S5).

Sex-associated expression of OPRM1 splice variants $m R N A$ in selected brain regions

Putting the mRNA expression of these splice variants in brain regions of male or female mice together couldn't show sex differences visually, thus we segregate variant expression by individual regions to provide another approach visualizing sex differences in different splice variants, and reveal significant comparisons (Fig. 6). The heatmap shows broad differences in expression of individual variants among the gender of most brain regions (Fig. 6), as does quantitative graphing where the expression level $\left(\mathrm{E}^{-\Delta(\mathrm{t})}\right)$ of each variant was plotted 


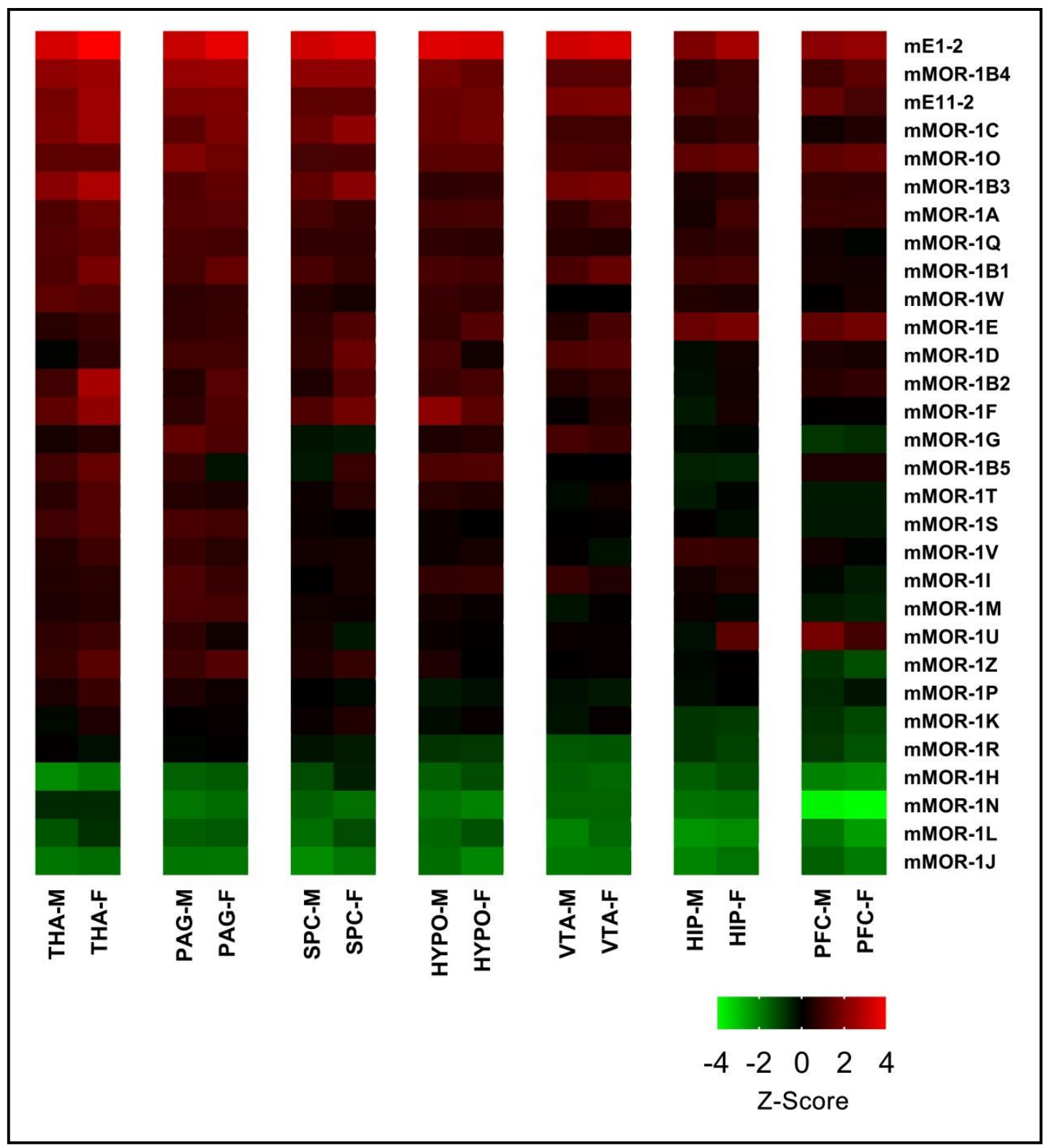

Fig. 6. Heatmap of expression of OPRM1 splice variant mRNAs among male and female mice. The heatmap was generated by clustering Z-scores calculated from the values $\left(\log _{2} E^{-\Delta c(t)}\right)$ of individual variants across different genders/regions using R statistical language, and plotting based upon individual gender within each brain region with enhanced heatmap function from GraphPad Prism 7.0. M: male; F: female. Expression level was indicated by Z-score.

by gender within each region (Fig. 7, S7, S8, S9 \& S10). Within a region on the heatmap, each column provides the relative expression of the different variants within the male or female mice whereas the horizontal comparisons reveal the gender differences for a specific variant.

Overall, among most variants, for instance, mMOR-1B3, mMOR-1B4, mMOR-1E, mMOR1F, mMOR-1G, mMOR-1H, mMOR-1K, mMOR-10, mMOR-1Q, mMOR-1W and mMOR-1Z, the mRNA expressions in the seven brain regions of male and female mice follow a similar trend approximately (Fig. 7, S7, S8, S9 \& S10). However, there were still a large number of significant differences in a certain brain region of male and female mice (Table S3). We investigated the expression levels of mE1-2 and mE11-2 and found that mE1-2 of female mice was higher in brain regions including the Tha, PAG and Hip compared with male mice whereas mE11- 

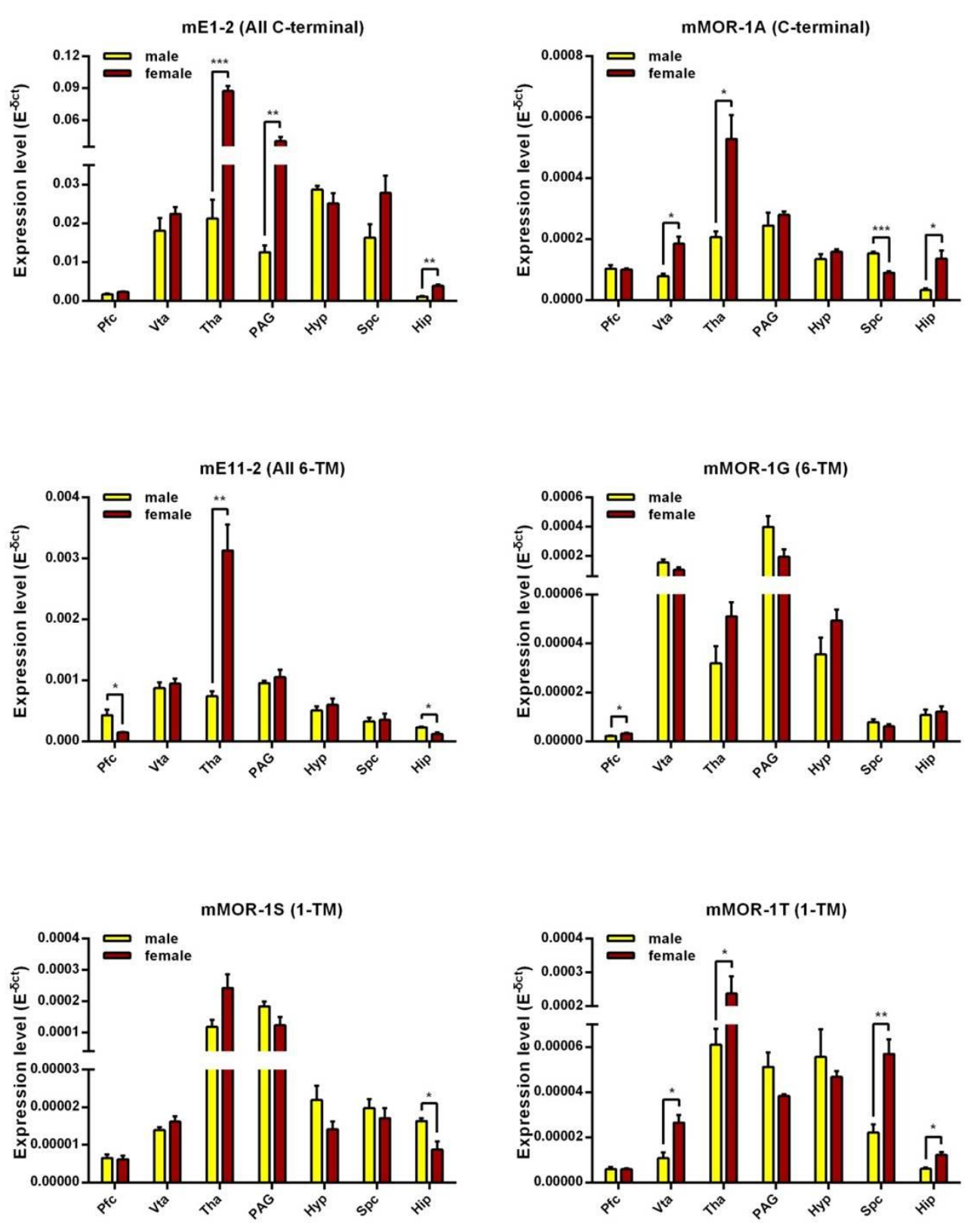

Fig. 7. Gender-specific expressions of OPRM1 splice variants. Each panel represents the expression of one variant in 7 regions of male and female mice. Yellow bar: male mice; Red bar: female mice. Bars represent the mean of $E^{-\Delta C(t)}$ values \pm S.E.M.. Significant difference was calculated by Two-way ANOVA with Tukey's multiple comparisons test for each variant. The results of the statistical analysis were listed in Table S3. The expression profiles of the other 24 OPRM1 splice variants are shown in Fig. S7, S8, S9 \& S10.

2 of female mice was lower in the Pfc and Hip, though mE11-2 was still higher in the Tha, compared with male mice. To sum up, in the Tha, 16 spliced variants revealed obvious sex differences which expressed diverse mRNA levels significantly, including mMOR-1A, mMOR1B1, mMOR-1B2, mMOR-1B3, mMOR-1B5, mMOR-1C, mMOR-1D, mMOR-1E, mMOR-1F, mMOR-1H, mMOR-1K, mMOR-1L, mMOR-1P, mMOR-1T, mMOR-1V, mMOR-1Z, and in other six brain regions, the number of the variants is 12 (mMOR-1B4, mMOR-1C, mMOR-1G, 
mMOR-1I, mMOR-1J, mMOR-1L, mMOR-1Q, mMOR-1R, mMOR-1U, mMOR-1V, mMOR-1W, mMOR-1Z, in the Pfc), 8 (mMOR-1A, mMOR-1E, mMOR-1F, mMOR-1I, mMOR-1L, mMOR1M, mMOR-1T, mMOR-1V, in the VTA), 12 (mMOR-1B1, mMOR-1B2, mMOR-1B5, mMOR-1C, mMOR-1F, mMOR-10, mMOR-1P, mMOR-1Q, mMOR-1R, mMOR-1U, mMOR-1V, mMOR-1Z, in the PAG), 7 (mMOR-1B4, mMOR-1C, mMOR-1D, mMOR-1F, mMOR-1N, mMOR-1R, mMOR1W, in the Hyp), 11 (mMOR-1A, mMOR-1B2, mMOR-1B3, mMOR-1D, mMOR-1F, mMOR1M, mMOR-10, mMOR-1P, mMOR-1S, mMOR-1T, mMOR-1U, in the Hip) and 14 (mMOR-1A, mMOR-1B1, mMOR-1B2, mMOR-1B3, mMOR-1B5, mMOR-1C, mMOR-1D, mMOR-1E, mMOR1F, mMOR-1H, mMOR-1I, mMOR-1T, mMOR-1U, mMOR-1Z, in the Spc), respectively (Table S5). Also, we calculated the number of the brain regions where sex differences existed, for example, with regard to mMOR-1F, there were six brain regions in which this mRNA levels were expressed differentially except the $\mathrm{Pfc}$, and as for mMOR-1C, the number was five while the mRNA levels of mMOR-1A, mMOR-1B2, mMOR-1D, mMOR-1T, mMOR-1U, mMOR-1V and mMOR-1Z were various in four brain regions, respectively (Table S4). Thus, we found that in every single brain region, sex differences of the mRNA expressions of C-terminal, 6-TM and 1-TM all existed.

Intriguingly, in all of the brain regions, the mRNA expressions of mMOR-1B2, mMOR1B3, mMOR-1C and mMOR-1E of female mice were higher compared with male mice (not statistically) whereas none of these splicing variants of male mice was higher than female mice in the seven brain regions (Fig. S7 \& S8). To sum up, the mRNA expression levels of 52 variants (including all brain regions) were higher in female mice compared with male mice, and in contrast 28 variants (including all brain regions) were higher in male mice compared with female mice (Table S4 \& S5). Although among most of the variants, the mRNA levels of female mice were higher compared with male mice (especially in the Tha, all variants of female mice were higher compared with male mice), this index of mMOR-1I, mMOR-1Q, mMOR-1R, mMOR-1U and mMOR-1V was higher in at least two brain regions of male mice compared with female mice apparently and statistically, especially in the Pfc and PAG (Table S4). Finally, the expression patterns of the variants within a brain region varied among the sexes. For example, in the PAG, the expression of mMOR-1B1, mMOR-1B2, mMOR-1C, mMOR-1F, mMOR-1R and mMOR-1Z in female mice was far higher than male mice, while in male mice the expression of mMOR-1B5, mMOR-10, mMOR-1P, mMOR-1Q, mMOR-1U and mMOR-1V was predominant (Fig. 7, S7, S8, S9 \& S10). A similar scenario was observed in the Pfc where the expressions of mMOR-1B4, mMOR-1C, mMOR-1G and mMOR-1W were much greater in female mice than male mice, whereas mMOR-1I, mMOR-1J, mMOR-1L, mMOR-1Q, mMOR-1R, mMOR-1U, mMOR-1V, mMOR-1Z were expressed higher in male mice. In the Spc, mMOR-1B2, mMOR-1B3, mMOR-1B5, mMOR-1D, mMOR-1E, mMOR-1F, mMOR1H, mMOR-1I, mMOR-1T and mMOR-1Z revealed higher expressions in female mice than male mice (Figs. 7, S7, S8, S9 \& S10). However, only mMOR-1I, mMOR-1V and mMOR-1M, mMOR-1S of male mice were higher than female mice in the VTA and Hip, respectively. Also, we investigated the expression of the variant which was highest in these seven regions and found that mMOR-1B3, mMOR-1B4 and mMOR-1E was highest in the VTA, PAG and Hip of both male and female mice, respectively, while mMOR-1B4 was highest in the Tha and Spc of male mice, mMOR-1C was highest in the Spc and Hyp of female mice, mMOR-1B3 was highest in the Tha of female mice, mMOR-1F was highest in the Hyp of male mice, mMOR-1E was highest in the Pfc of female mice, mMOR-1U was highest in the Pfc of male mice, respectively (Fig. 4 \& 6, Table S2). Together, these results suggested sex-associated expression of OPRM1 splice variants $\mathrm{mRNA}$ in selected brain regions.

\section{Discussion}

The current study used both male and female C57BL/6 mouse models to investigate the correlation of sex differences in baseline latency, opioid-induced therapeutic action, side effects and expressions of the alternatively spliced variants mRNA of OPRM1. It was 
demonstrated that sex differences actually existed, consisting with previous studies $[6,7,22$, $26,45,46]$, and the mRNA expressions of these variants were region-specific and also genderspecific, in accordance with our previous study partially [33]. Our results indicated that pain threshold of male mice against thermal stimulus and morphine-induced analgesic potency was higher in male mice compared with female mice and female mice was more easily to generate morphine tolerance. However, male mice revealed extremely obvious physical dependence on chronic morphine subcutaneous injection, i.e. more intensive withdrawal reactions than female mice, just like the humans since a profile of a heroin-addiction epidemic showed that 74 percent of the addicts are males [7]. Also, our data demonstrated that there were abundant and remarked distinctions among the OPRM1 splicing variants in selected brain regions of both male and female mice, an identification of the vast and sophisticated array of mRNA expressions. Although it was proposed that sex differences in opioid analgesia and addiction resulted from interactions among opioid receptors and estrogen receptors, $\kappa$ opioid pharmacology and function, sex chromosome genes (X and Y gene with the testis-determining Sry gene deleted), and different brain regions (e.g., PAG, trigeminal ganglia and hippocampal mossy fiber) [7, 24-26, 36, 37, 47], we devoted to shed light on the relationship between these differences and OPRM1 alternative splicing through detecting the mRNA levels of variants by SYBR green qPCR.

For decades, several classic techniques and approaches were employed to identify splice variants of the $\mu$ opioid receptor gene, for example, autoradiography provided the earliest means while in situ hybridation following the cloning using probes examined the distribution of these receptors immunohistochemically [48-55]. Although previous studies have provided valuable insights into opioid action, they all have limitations, including requiring active binding of ligand, labeling more than one species and not targeting all the variants. We also tried traditional RT-PCR approaches to examine the expression of OPRM1 splice variants mRNA in brain regions [56-59]. However, these early approaches provided only approximate levels since they were not quantitative. The present study using SYBR green qPCR overcomes these limitations and more precisely quantifies the expression of OPRM1 splice variant mRNAs. Despite these assays didn't provide anatomical resolution at the cellular level and address their expression at the protein level, we made a step toward our understanding of a complete OPRM1 splice variant expression in brain regions of both male and female mice for the first time.

Our results illustrated a wide range of expression levels among the variants which gives rise to the comparison and contrast between male and female mice more complicated and intriguing. Generally speaking, most of C-terminal splice variants were highly expressed while truncated 6-TM variants and single TM variants were mixed and mRNA expression was higher in the Tha and PAG compared with that in the Hip and Pfc. Sex differences of these variants levels mainly existed in the Tha and Spc and reflected by mMOR-1F, mMOR-1C, mMOR-1A, mMOR-1B2, mMOR-1D, mMOR-1T, mMOR-1U, mMOR-1V, mMOR-1Z. However, we should not ignore other characteristics and distinctions. Meanwhile, the sex differences of these splice variants and the different reactions and behaviors of male and female mice in the baseline latency and opioid-induced ethology should not be straightforwardly correlated and corresponded. Previous studies demonstrated that mMOR-1D was implicated in morphineinduced itch through its dimerization with gastrinreleasing peptide receptor (GRPR) despite its low mRNA levels [60]. Exon 11-associated 6-TM variants were also among the low abundant transcripts. Yet, an exon 11 knockout mouse model indicated a key role of these 6-TM variants in the analgesic actions of a range of opioids, including heroin, M6G, fentanyl, levorphanol and buprenorphine [18]. These 6-TM variants also were critical in the actions of a novel class of opioid analgesic exemplified by 3 '-iodobenzoyl-6 $\beta$-naltexamide (IBNtxA), which was interesting since IBNtxA produces potent analgesia without many traditional opioid side-effects such as respiratory depression, physical dependence and reward behavior, mediated by exon 11-associated splice variants of the mu-opioid receptor gene $[18,19,61]$. The importance of 6-TM variants was further supported by recent studies showing the rescue of IBNtxA analgesia in knockout mice lacking 6-TM variants that were insensitive to IBNtxA 
by the lentiviral-mediated delivery of a 6-TM variant, mMOR-1G. It was reported that mMOR$1 \mathrm{~K}$, which exhibited excitatory cellular signaling, was elevated in HIV-infected individuals with combined neurocognitive impairment (NCI) and HIV encephalitis (HIVE) in relation to $\beta$-Adrenergic receptor and the inflammatory mediators MCP-1, MCP-2, and RANTES [62, $63]$. In addition, the $129 \mathrm{~S} 6$ mice exhibited an analgesic response correlating to a measured decrease in MOR-1K gene expression levels, while CXB7/ByJ mice exhibited a hyperalgesic response correlating to a measured increase in MOR-1K gene expression levels, revealing that mMOR-1K contributes to the development of opioid-induced hyperalgesia [64]. Also, we had found that in mE7M-B6 mice (C-terminal tails encoded by exon 7 selectively truncated), the exon 7-associated truncation diminished morphine tolerance and reward without altering physical dependence, whereas the exon 4-associated truncation in mE4M-B6 (C-terminal tails encoded by exon 4 selectively truncated) mice facilitated morphine tolerance and reduced morphine dependence without affecting morphine reward [38]. Although the mRNA levels of individual 7-TM variants mMOR-1A, mMOR-1D, mMOR-1I, and mMOR-10, 6-TM variants mMOR-1G and mMOR-1K, and the single TM variants mMOR-1S and mMOR$1 \mathrm{R}$ were not appreciably altered in homozygous mice of all the models $(\mathrm{mE} 3 \mathrm{M}, \mathrm{mE} 4 \mathrm{M}$ and $\mathrm{mE7M}$ ), the mRNA levels of mMOR-1C and MMOR-1M were greatly reduced in both the mE3M and mE7M mouse models [38]. Besides, long-term morphine treatment selectively increased C-terminal variant mRNA expression in various brain regions by as much as 300-fold [39], and at the protein level, different C-terminal epitopes also differed in their cellular (i.e., prevs. postsynaptic) and regional distributions $[65,66]$. While the exon 4 epitope was contained within a number of 7-TM variants (mMOR-1, mMOR-1H, mMOR-1I, and mMOR-1J) as well as a 6-TM variant (mMOR-1G) and the exon 7-encoded sequence is present in 7-TM variants (mMOR-1C, mMOR-10, and mMOR-1U) as well as the 6-TM variant mMOR-1M, assigning a specific variant was not possible due to concurrent $5^{\prime}$ alternative splicing though the models dissociate the actions of different groups of C-terminal splice variants [38]. Other findings include that activation of mMOR-1C may be one mechanism by which glutamate release is inhibited, naloxone methiodide may represent a possible remedy for opioid-induced itching, MOR C-terminus phosphorylation does not appear to be critical for morphine tolerance in vivo and MOR-TRPV1 crosstalk in TRPV1 activation involves in morphine antinociception, tolerance and dependence [67-70]. Overall, analgesic effect of opioid agonist primarily results from exon 11-associated 6-TM variants [71], morphine-induced itch is mainly due to heterodimerization of 7-TM C-terminal variant mMOR-1D with gastrin-releasing peptide receptor and opioid-induced tolerance and physical dependence is partially dominated by mE7M (especially mMOR-1C and mMOR-10 at mRNA levels) and $\mathrm{mE} 4 \mathrm{M}$, respectively. Thus, we can approximately figure out the correlation between sex differences of ethology and differential mRNA levels of OPRM1 splice variants in male and female mice. Present study revealed that the mRNA expression of mMOR-1C was higher in the PAG of female mice compared with male mice while mMOR-10 was higher in the same brain region of male mice compared with female mice statistically. Since previous studies were focusing on the PAG $[6,36]$ to explore sex differences, we proposed that the distinctions of mMOR-1C and mMOR-10 between male and female mice might contribute to their different behavior in opioid-induced tolerance. The 6-TM splice variant mMOR-1K was reported to correlate with the development of opioid-induced hyperalgesia, combining our results (mMOR-1K was higher in female mice than male mice), we should continue to investigate this variant in the Tha. Exon 4-associated variants mainly include mMOR-1H, mMOR-1I, mMOR-1J and mMOR$1 \mathrm{G}$, and intriguingly sex differences among these variants existed in the Pfc, where most of the variants showed lower expression. An investigation of 6-TM variants which give rise to the analgesic effect of opioid agonist demonstrated that mMOR-1G, mMOR-1K, mMOR-1L, mMOR-1M, mMOR-1N of male and female mice were all expressed differentially in several brain regions (Pfc, Tha and VTA). As for itching, the expression of mMOR-1D was higher in female mice compared with male in the Tha, Spc and Hip and in contrast, this index of male mice was higher in the Hyp.

Although our results explained the relationship between sex differences from the

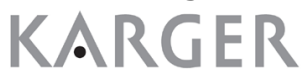


perspective of OPRM1 alternatively splicing variants, there were still a few limitations. Pharmacological actions of $\mu$ opioid receptors was partially dominated by exons [38], which might influence mRNA expression but could not explain all the differences. For example, within each group, mRNA levels vary, as shown by the far lower levels of mMOR-1B5 and mMOR-1P levels than those of mMOR-1B4, mMOR-10 and mMOR-1C in most of the brain regions. However, mRNA stability also may impact expression levels. Particularly, nonsensemediated decay (NMD) which is a surveillance pathway that exists in all eukaryotes reducing errors in gene expression by eliminating mRNA transcripts that contain premature stop codons [72-74]. Eight variants, including mMOR-1E, mMOR-1F, mMOR-1Q, mMOR-1R, mMOR-1T, mMOR-1V, mMOR-1W, and mMOR-1Z, are potential targets of NMD, which seems not solely one factor influencing mRNA expression levels. Moreover, mRNA levels may not correlate with either their corresponding protein expression or with their pharmacological importance, and on the contrary, drugs may also influence the mRNA expression of these variants [69]. Male and female mice presumably differing in the modulation of the promoters and alternative splicing machinery, such as single nucleotide polymorphisms (SNPs), deletions, insertions and transposon elements, may explain why the very different pattern of the variant expression is generated from the same single-copy OPRM1 gene. Therefore, the present study advances our knowledge on the OPRM1 alternative splicing in male and female mice and it will be important to develop a reliable and precise method for determining protein expression of these OPRM1 splice variants in the future.

\section{Acknowledgements}

This work was supported, in part, by grants from a National Natural Science Foundation of China grant (81673412) to Z.-G.L.

\section{Disclosure Statement}

The authors declare no competing financial interests.

\section{References}

1 Pasternak GW: Pharmacological mechanisms of opioid analgesics. Clin Neuropharmacol 1993;16:1-18.

2 Roeckel LA, Utard V, Reiss D, Mouheiche J, Maurin H, Robe A, Audouard E, Wood JN, Goumon Y, Simonin F, Gaveriaux-Ruff C: Morphine-induced hyperalgesia involves mu opioid receptors and the metabolite morphine-3-glucuronide. Sci Rep 2017;7:10406.

3 Baamonde AI, Hidalgo A, Andres-Trelles F: Sex-related differences in the effects of morphine and stress on visceral pain. Neuropharmacology 1989;28:967-970.

4 Cicero TJ, Nock B, Meyer ER: Gender-related differences in the antinociceptive properties of morphine. J Pharmacol Exp Ther 1996;279:767-773.

5 Mogil JS, Chesler EJ, Wilson SG, Juraska JM, Sternberg WF: Sex differences in thermal nociception and morphine antinociception in rodents depend on genotype. Neurosci Biobehav Rev 2000;24:375-389.

-6 Bernal SA, Morgan MM, Craft RM: PAG mu opioid receptor activation underlies sex differences in morphine antinociception. Behav Brain Res 2007;177:126-133.

7 Lee CW, Ho IK: Sex differences in opioid analgesia and addiction: interactions among opioid receptors and estrogen receptors. Mol Pain 2013;9:45.

-8 Leipzig J, Pevzner P, Heber S: The Alternative Splicing Gallery (ASG): bridging the gap between genome and transcriptome. Nucleic Acids Res 2004;32:3977-3983.

-9 Rossi GC, Pan YX, Brown GP, Pasternak GW: Antisense mapping the MOR-1 opioid receptor: evidence for alternative splicing and a novel morphine-6 beta-glucuronide receptor. FEBS Lett 1995;369:192-196. 


\section{Cellular Physiology Cell Physiol Biochem 2018;50:1441-1459 \begin{tabular}{l|l|l|l} 
DOI: 10.1159/000494644 & O 2018 The Author(s). Published by S. Karger AG, Basel \\
wwww.karger.com/cpb
\end{tabular}

Liu et al.: Sex Differences of OPRM1 in Mouse Brain Regions

10 Rossi GC, Leventhal L, Pan YX, Cole J, Su W, Bodnar RJ, Pasternak GW: Antisense mapping of MOR-1 in rats: distinguishing between morphine and morphine-6beta-glucuronide antinociception. J Pharmacol Exp Ther 1997;281:109-114.

11 Chen Y, Mestek A, Liu J, Hurley JA, Yu L: Molecular cloning and functional expression of a mu-opioid receptor from rat brain. Mol Pharmacol 1993;44:8-12.

12 Wang JB, Imai Y, Eppler CM, Gregor P, Spivak CE, Uhl GR: mu opiate receptor: cDNA cloning and expression. Proc Natl Acad Sci U S A 1993;90:10230-10234.

13 Thompson RC, Mansour A, Akil H, Watson SJ: Cloning and pharmacological characterization of a rat mu opioid receptor. Neuron 1993;11:903-913.

14 Pan YX: Diversity and complexity of the mu opioid receptor gene: alternative pre-mRNA splicing and promoters. DNA Cell Biol 2005;24:736-750.

15 Pasternak GW: Molecular insights into mu opioid pharmacology: From the clinic to the bench. Clin J Pain 2010;26 Suppl 10:S3-9.

16 Pasternak GW, Pan YX: Mu opioids and their receptors: evolution of a concept. Pharmacol Rev 2013;65:1257-1317.

17 Kilpatrick GJ, Smith TW: Morphine-6-glucuronide: actions and mechanisms. Med Res Rev 2005;25:521544.

18 Pan YX, Xu J, Xu M, Rossi GC, Matulonis JE, Pasternak GW: Involvement of exon 11-associated variants of the mu opioid receptor MOR-1 in heroin, but not morphine, actions. Proc Natl Acad Sci U S A 2009;106:49174922.

19 Majumdar S, Grinnell S, Le Rouzic V, Burgman M, Polikar L, Ansonoff M, Pintar J, Pan YX, Pasternak GW: Truncated G protein-coupled mu opioid receptor MOR-1 splice variants are targets for highly potent opioid analgesics lacking side effects. Proc Natl Acad Sci U S A 2011;108:19778-19783.

20 Petrovich DV: The Pain Apperception Test: an application to sex differences. J Clin Psychol 1959;15:412414.

-21 Streicher E, Garbus J: The effect of age and sex on the duration of hexobarbital anesthesia in rats. J Gerontol 1955;10:441-444.

22 Mitrovic I, Margeta-Mitrovic M, Bader S, Stoffel M, Jan LY, Basbaum AI: Contribution of GIRK2-mediated postsynaptic signaling to opiate and alpha 2-adrenergic analgesia and analgesic sex differences. Proc Natl Acad Sci U S A 2003;100:271-276.

23 Bobeck EN, McNeal AL, Morgan MM: Drug dependent sex-differences in periaqueducatal gray mediated antinociception in the rat. Pain 2009;147:210-216.

24 Gioiosa L, Chen X, Watkins R, Klanfer N, Bryant CD, Evans CJ, Arnold AP: Sex chromosome complement affects nociception in tests of acute and chronic exposure to morphine in mice. Horm Behav 2008;53:124130.

25 Rasakham K, Liu-Chen LY: Sex differences in kappa opioid pharmacology. Life Sci 2011;88:2-16.

26 Harte-Hargrove LC, Varga-Wesson A, Duffy AM, Milner TA, Scharfman HE: Opioid receptor-dependent sex differences in synaptic plasticity in the hippocampal mossy fiber pathway of the adult rat. J Neurosci 2015;35:1723-1738.

-27 Mogil JS, Sternberg WF, Kest B, Marek P, Liebeskind JC: Sex differences in the antagonism of swim stressinduced analgesia: effects of gonadectomy and estrogen replacement. Pain 1993;53:17-25.

-28 Mogil JS, Wilson SG, Chesler EJ, Rankin AL, Nemmani KV, Lariviere WR, Groce MK, Wallace MR, Kaplan L, Staud R, Ness TJ, Glover TL, Stankova M, Mayorov A, Hruby VJ, Grisel JE, Fillingim RB: The melanocortin-1 receptor gene mediates female-specific mechanisms of analgesia in mice and humans. Proc Natl Acad Sci U S A 2003;100:4867-4872.

29 Rasakham K, McGillivray KL, Liu-Chen LY: Sex differences in U50, 488H-induced phosphorylation of p44/42 mitogen-activated protein kinase in the guinea pig brain. Neuroscience 2012;223:447-456.

-30 Loyd DR, Murphy AZ: The neuroanatomy of sexual dimorphism in opioid analgesia. Exp Neurol 2014;259:57-63.

31 Cook CD, Barrett AC, Roach EL, Bowman JR, Picker MJ: Sex-related differences in the antinociceptive effects of opioids: importance of rat genotype, nociceptive stimulus intensity, and efficacy at the mu opioid receptor. Psychopharmacology (Berl) 2000;150:430-442.

-32 Craft RM: Sex differences in opioid analgesia: "from mouse to man". Clin J Pain 2003;19:175-186. 


\section{Cellular Physiology Cell Physiol Biochem 2018;50:1441-1459 \begin{tabular}{ll|l} 
and Biochemistry Published online: 26 October 2018 & $\begin{array}{l}\odot 2018 \text { The Author(s). Published by S. Karger AG, Basel } \\
\text { www.karger.com/cpb }\end{array}$ \\
\hline
\end{tabular}}

Liu et al.: Sex Differences of OPRM1 in Mouse Brain Regions

33 Xu J, Lu Z, Xu M, Rossi GC, Kest B, Waxman AR, Pasternak GW, Pan YX: Differential expressions of the alternatively spliced variant mRNAs of the micro opioid receptor gene, OPRM1, in brain regions of four inbred mouse strains. PLoS One 2014;9:e111267.

34 Bai X, Zhang X, Li Y, Lu L, Li B, He X: Sex differences in peripheral mu-opioid receptor mediated analgesia in rat orofacial persistent pain model. PLoS One 2015;10:e0122924.

35 Verzillo V, Madia PA, Liu NJ, Chakrabarti S, Gintzler AR: Mu-opioid receptor splice variants: sex-dependent regulation by chronic morphine. J Neurochem 2014;130:790-796.

-36 Loyd DR, Wang X, Murphy AZ: Sex differences in micro-opioid receptor expression in the rat midbrain periaqueductal gray are essential for eliciting sex differences in morphine analgesia. J Neurosci 2008;28:14007-14017.

-37 Zhang X, Zhang Y, Asgar J, Niu KY, Lee J, Lee KS, Schneider M, Ro JY: Sex differences in mu-opioid receptor expression in trigeminal ganglia under a myositis condition in rats. Eur J Pain 2014;18:151-161.

-38 Xu J, Lu Z, Narayan A, Le Rouzic VP, Xu M, Hunkele A, Brown TG, Hoefer WF, Rossi GC, Rice RC, MartinezRivera A, Rajadhyaksha AM, Cartegni L, Bassoni DL, Pasternak GW, Pan YX: Alternatively spliced mu opioid receptor $C$ termini impact the diverse actions of morphine. J Clin Invest 2017;127:1561-1573.

39 Xu J, Faskowitz AJ, Rossi GC, Xu M, Lu Z, Pan YX, Pasternak GW: Stabilization of morphine tolerance with long-term dosing: association with selective upregulation of mu-opioid receptor splice variant mRNAs. Proc Natl Acad Sci U S A 2015;112:279-284.

40 Paxinos G, Franklin K: Mouse brain in stereotaxic coordinates, ed 3, revised. San Diego, ACADEMIC PRESS, 2001.

-41 Pfaffl MW: A new mathematical model for relative quantification in real-time RT-PCR. Nucleic Acids Res 2001;29:e45.

-42 Vandesompele J, De Preter K, Pattyn F, Poppe B, Van Roy N, De Paepe A, Speleman F: Accurate normalization of real-time quantitative RT-PCR data by geometric averaging of multiple internal control genes. Genome Biol 2002;3:RESEARCH0034.

43 Pfaffl MW, Tichopad A, Prgomet C, Neuvians TP: Determination of stable housekeeping genes, differentially regulated target genes and sample integrity: BestKeeper--Excel-based tool using pair-wise correlations. Biotechnol Lett 2004;26:509-515.

44 Kaufman DL, Keith DE, Jr., Anton B, Tian J, Magendzo K, Newman D, Tran TH, Lee DS, Wen C, Xia YR, et al.: Characterization of the murine mu opioid receptor gene. J Biol Chem 1995;270:15877-15883.

45 Musey PI, Jr., Linnstaedt SD, Platts-Mills TF, Miner JR, Bortsov AV, Safdar B, Bijur P, Rosenau A, Tsze DS, Chang AK, Dorai S, Engel KG, Feldman JA, Fusaro AM, Lee DC, Rosenberg M, Keefe FJ, Peak DA, Nam CS, Patel RG, Fillingim RB, McLean SA: Gender differences in acute and chronic pain in the emergency department: results of the 2014 Academic Emergency Medicine consensus conference pain section. Acad Emerg Med 2014;21:1421-1430.

46 Manubay J, Davidson J, Vosburg S, Jones J, Comer S, Sullivan M: Sex differences among opioid-abusing patients with chronic pain in a clinical trial. J Addict Med 2015;9:46-52.

-47 Chartoff EH, Mavrikaki M: Sex Differences in Kappa Opioid Receptor Function and Their Potential Impact on Addiction. Front Neurosci 2015;9:466.

-48 Atweh SF, Kuhar MJ: Distribution and physiological significance of opioid receptors in the brain. Br Med Bull 1983;39:47-52.

49 Atweh SF, Kuhar MJ: Autoradiographic localization of opiate receptors in rat brain. III. The telencephalon. Brain Res 1977;134:393-405.

50 Mansour A, Khachaturian H, Lewis ME, Akil H, Watson SJ: Autoradiographic differentiation of mu, delta, and kappa opioid receptors in the rat forebrain and midbrain. J Neurosci 1987; 7:2445-2464.

51 Mansour A, Fox CA, Burke S, Akil H, Watson SJ: Immunohistochemical localization of the cloned mu opioid receptor in the rat CNS. J Chem Neuroanat 1995;8:283-305.

52 Hiller JM, Zhang Y, Bing G, Gioannini TL, Stone EA, Simon EJ: Immunohistochemical localization of muopioid receptors in rat brain using antibodies generated against a peptide sequence present in a purified mu-opioid binding protein. Neuroscience 1994;62:829-841.

-53 Mansour A, Fox CA, Burke S, Meng F, Thompson RC, Akil H, Watson SJ: Mu, delta, and kappa opioid receptor mRNA expression in the rat CNS: an in situ hybridization study. J Comp Neurol 1994;350:412-438. 


\section{Cellular Physiology Cell Physiol Biochem 2018;50:1441-1459 \begin{tabular}{l|l|l} 
and Biochemistry & DOI: 10.1159/000494644 & $\begin{array}{l}\text { C } 2018 \text { The Author(s). Published by S. Karger AG, Basel } \\
\text { www.karger.com/cpb }\end{array}$
\end{tabular}

Liu et al.: Sex Differences of OPRM1 in Mouse Brain Regions

54 Arvidsson U, Riedl M, Chakrabarti S, Lee JH, Nakano AH, Dado RJ, Loh HH, Law PY, Wessendorf MW, Elde R: Distribution and targeting of a mu-opioid receptor (MOR1) in brain and spinal cord. J Neurosci 1995;15:3328-3341.

55 Honda CN, Arvidsson U: Immunohistochemical localization of delta- and mu-opioid receptors in primate spinal cord. Neuroreport 1995;6:1025-1028.

56 Pan YX, Xu J, Bolan E, Abbadie C, Chang A, Zuckerman A, Rossi G, Pasternak GW: Identification and characterization of three new alternatively spliced mu-opioid receptor isoforms. Mol Pharmacol 1999;56:396-403.

-57 Pan YX, Xu J, Bolan E, Chang A, Mahurter L, Rossi G, Pasternak GW: Isolation and expression of a novel alternatively spliced mu opioid receptor isoform, MOR-1F. FEBS Lett 2000;466:337-340.

58 Pan YX, Xu J, Mahurter L, Bolan E, Xu M, Pasternak GW: Generation of the mu opioid receptor (MOR-1) protein by three new splice variants of the Oprm gene. Proc Natl Acad Sci U S A 2001;98:14084-14089.

59 Pan L, Xu J, Yu R, Xu MM, Pan YX, Pasternak GW: Identification and characterization of six new alternatively spliced variants of the human mu opioid receptor gene, Oprm. Neuroscience 2005;133:209-220.

60 Liu XY, Liu ZC, Sun YG, Ross M, Kim S, Tsai FF, Li QF, Jeffry J, Kim JY, Loh HH, Chen ZF: Unidirectional crossactivation of GRPR by MOR1D uncouples itch and analgesia induced by opioids. Cell 2011;147:447-458.

61 Wieskopf JS, Pan YX, Marcovitz J, Tuttle AH, Majumdar S, Pidakala J, Pasternak GW, Mogil JS: Broadspectrum analgesic efficacy of IBNtxA is mediated by exon 11-associated splice variants of the mu-opioid receptor gene. Pain 2014;155:2063-2070.

-62 Dever SM, Rodriguez M, El-Hage N: beta-Adrenergic receptor gene expression in HIV-associated neurocognitive impairment and encephalitis: implications for MOR-1K subcellular localization. J Neurovirol 2016;22:866-870.

-63 Dever SM, Costin BN, Xu R, El-Hage N, Balinang J, Samoshkin A, O’Brien MA, McRae M, Diatchenko L, Knapp PE, Hauser KF: Differential expression of the alternatively spliced OPRM1 isoform mu-opioid receptor-1K in HIV-infected individuals. AIDS 2014;28:19-30.

64 Oladosu FA, Conrad MS, O’Buckley SC, Rashid NU, Slade GD, Nackley AG: Mu Opioid Splice Variant MOR-1K Contributes to the Development of Opioid-Induced Hyperalgesia. PLoS One 2015;10:e0135711.

65 Abbadie C, Pan Y, Drake CT, Pasternak GW: Comparative immunohistochemical distributions of carboxy terminus epitopes from the mu-opioid receptor splice variants MOR-1D, MOR-1 and MOR-1C in the mouse and rat CNS. Neuroscience 2000;100:141-153.

66 Abbadie C, Pasternak GW, Aicher SA: Presynaptic localization of the carboxy-terminus epitopes of the mu opioid receptor splice variants MOR-1C and MOR-1D in the superficial laminae of the rat spinal cord. Neuroscience 2001;106:833-842.

67 Schnell SA, Wessendorf MW: Coexpression of the mu-opioid receptor splice variant MOR1C and the vesicular glutamate transporter 2 (VGLUT2) in rat central nervous system. J Comp Neurol 2008;508:542564.

68 Yamamoto A, Sugimoto Y: Involvement of peripheral mu opioid receptors in scratching behavior in mice. Eur J Pharmacol 2010;649:336-341.

69 Kibaly C, Lin HY, Loh HH, Law PY: Spinal or supraspinal phosphorylation deficiency at the MOR C-terminus does not affect morphine tolerance in vivo. Pharmacol Res 2017;119:153-168.

70 Bao Y, Gao Y, Yang L, Kong X, Yu J, Hou W, Hua B: The mechanism of mu-opioid receptor (MOR)-TRPV1 crosstalk in TRPV1 activation involves morphine anti-nociception, tolerance and dependence. Channels (Austin) 2015;9:235-243.

71 Majumdar S, Subrath J, Le Rouzic V, Polikar L, Burgman M, Nagakura K, Ocampo J, Haselton N, Pasternak AR, Grinnell S, Pan YX, Pasternak GW: Synthesis and evaluation of aryl-naloxamide opiate analgesics targeting truncated exon 11-associated mu opioid receptor (MOR-1) splice variants. J Med Chem 2012;55:6352-6362.

72 Lejeune F, Maquat LE: Mechanistic links between nonsense-mediated mRNA decay and pre-mRNA splicing in mammalian cells. Curr Opin Cell Biol 2005;17:309-315.

73 Chang YF, Imam JS, Wilkinson MF: The nonsense-mediated decay RNA surveillance pathway. Annu Rev Biochem 2007;76:51-74.

74 He F, Jacobson A: Nonsense-Mediated mRNA Decay: Degradation of Defective Transcripts Is Only Part of the Story. Annu Rev Genet 2015;49:339-366. 